\title{
Analisis Kinerja Aplikasi Sistem Informasi Cuti Elektronik Dengan Menggunakan IT Balanced Scorecard
}

\author{
Neti Triana ${ }^{1}$, Frederik Samuel Papilaya ${ }^{2}$ \\ ${ }^{1,2}$ Universitas Kristen Satya Wacana; \\ J1. Diponegoro No. 52-60, Kota Salatiga, Kec. Sidorejo, Jawa Tengah 50711, \\ (0298) 3212121 \\ ${ }^{3}$ Jurusan Sistem Informasi, FTI UKSW, Salatiga \\ e-mail: *11netitriana03@gmail.com, ${ }^{2}$ samuel.papilaya@uksw.edu
}

\begin{abstract}
Abstrak
Badan Kepegawaian, Pelatihan dan Pendidikan (BKDIKLATDA) Kota Salatiga merupakan lembaga pemerintahan yang bergerak dibidang kepegawaian. Kinerja suatu aplikasi perlu untuk menjadi perhatian karena kinerja dari sebuah aplikasi menjadi faktor penting yang memberikan informasi terhadap kinerja penggunaan dari aplikasi. Maka dari itu peneliti melakukan pengukuran dari kinerja aplikasi sistem informasi cuti elektronik (SiCute) untuk melihat seberapa besar tingkat kesuksesan kinerja dari suatu aplikasi terhadap tujuan yang ingin dicapai dari penerapanya yang merupakan salah satu sistem informasi yang digunakan oleh Badan Kepegawaian, Pelatihan dan Pendidikan Kota Salatiga. dimana pada penelitian ini peneliti menggunakan metode IT Balanced Scorecard yang didalamnya terdapat empat perspektif diantaranya perspektif kontribusi organisasi, perspektif orientasi pengguna, perspektif keunggulan operasional dan perspektif orientasi masa depan. Dari penelitian ini diperoleh hasil pada perspektif orientasi pengguna mendapat nilai tertinggi sebesar 24,18\%, perspektif keunggulan operasional 24,07, perspektif kontribusi organisasi sebesar 23,77, dan nilai yang terakhir yaitu perspektif orientasi masa depan sebesar 20,29\%. Dilihat dari hasil pencapaian tiap perspektif ini sudah berada pada kondisi sangat baik dengan total hasil pengukuran sebesar $92,94 \%$
\end{abstract}

Kata Kunci-aplikasi, pengukuran kinerja, IT Balanced Scorecard

\section{Abstract}

Agency for Staffing, Training and Education (BKDIKLATDA) Salatiga City is a government institution engaged in personnel. The performance of an application needs to be a concern because the performance of an application becomes an important factor that informs the performance of the use of the application. Therefore, the researchers measured the performance of electronic leave information system (SiCute) application to see how much the success rate of performance of an application against the goal to be achieved from its application which is one of the information systems used by the Agency for Staffing, Training and Education of Salatiga City. where in this study researchers use THE Balanced Scorecard method in which there is a perspective empet including perspective of organizational contribution, perspective of user orientation, perspective of operational excellence and perspective of future orientation. From this study obtained results on the perspective of user orientation got the highest score of $24.18 \%$, perspective of operasional excellence 24.07, perspective of organizational contribution of 23.77, and the last value of future orientation perspective of 20.29\%. Judging from the results of the achievement of each perspective is already in very good condition with a total measurement result of $92.94 \%$ 
Keywords-application, performance measurement, IT Balanced Scorecard

\section{PENDAHULUAN}

Sistem informasi merupakan sistem yang digunakan sebagai penyedia informasi bagi perusahaan untuk memanajemen dalam pengambilan keputusan. Sistem informasi yang baik akan menghasilkan kinerja yang baik pula bagi perusahaan. Kinerja perusahaan merupakan hasil dari proses kegiatan perusahaan dalam kurun waktu tertentu dengan mengacu pada kebijakan yang ditetapkan. Dengan demikian sistem informasi berperan penting untuk memudahkan kegiatan operasional serta dalam penyajian informasi yang akurat. Pemanfaatan sistem informasi memberikan banyak nilai tambah dalam meningkatkan efektivitas perusahaan, namun penerapan sistem informasi perlu untuk diperhatikan secara mendalam karena penerapan sistem informasi yang kurang tepat bisa menimbulkan permasalahan. Oleh karena itu perlu untuk dilakukan pengukuran kinerja sistem informasi yang digunakan saat ini. Pengukuran kinerja merupakan faktor penting dalam dunia bisnis untuk mengetahui efektifitas dan strategi penerapan agar mencapai tujuan yang strategis [1].

Badan Kepegawaian, Pelatihan dan Pendidikan (BKDIKLATDA) Kota Salatiga merupakan lembaga yang bergerak dibidang kepegawaian. BKDIKLATDA tidak luput dari perkembangan teknologi informasi untuk menjalankan kegiatan operasional dengan memanfaatkan sistem informasi. Saat ini BKDIKLATDA sudah mengimplementasikan berbagai sistem dan aplikasi, salah satu SI tersebut adalah sistem informasi Cuti Elektronik (SiCute). SiCute adalah aplikasi yang digunakan untuk mempermudah penyimpanan data dan penyampaian informasi pengajuan cuti Pegawai Negeri Sipil (PNS) kota salatiga. Sistem aplikasi ini memiliki fungsi utama sebagai pengajuan cuti Pegawai Negeri Sipil (PNS) untuk cuti tahunan, cuti bersama, cuti bersalin, cuti alasan penting, cuti hari besar dan cuti diluar tanggungan negara untuk mendukung kinerja pegawai agar dapat memproses data lebih tertata dan cepat. Aplikasi SiCute dapat diakses kapanpun oleh setiap PNS.

Berdasarkan survey awal, dalam penerapan SiCute pada BKDIKLATDA sampai saat ini belum dilakukan pengukuran kinerja sistem SiCute pada BKDIKLATDA Salatiga. Maka perlu untuk dilakukan pengukuran kinerja sistem informasi Cuti Elektronik untuk mengetahui seberapa besar tingkat kesuksesan kinerja aplikasi SiCute. Pengukuran kinerja aplikasi merupakan cara untuk mendapatkan informasi mengenai kinerja dari aplikasi yang digunakan, sehingga dari hasil pengukuran ini dapat diperoleh suatu nilai yang mewakili sejauh mana tingkat kinerja aplikasi yang ada saat ini dibandingkan dengan tujuan yang ingin dicapai dari penerapannya [2]. Pengukuran kinerja aplikasi teknologi informasi dimaksudkan untuk mengetahui masing-masing perspektif, yaitu kontribusi organisasi, orientasi pengguna, kesempurnaan operasional, dan orientasi masa depan dengan menggunakan metode IT Balanced Scorecard [3]. IT Balanced Scorecard menyediakan pemaparan dan ulasan yang bersifat menyeluruh dan terstruktur, sehingga pengelola sistem informasi dapat terus memantau perkembangan setiap aspek dari strategi penerapan teknologi informasi dengan mengacu kepada nilai dari masing-masing perspektif [4].

Penelitian terdahulu yang berjudul "Analisis Kinerja SI/TI Pada PDAM Kota Salatiga Menggunakan Kerangka IT Balanced Scorecard". pengumpulan data dikumpulkan dengan wawancara dan observasi. Tujuan penelitian ini adalah untuk menganalisis kinerja SI/TI pada PDAM Kota Salatiga dengan menggunakan metode IT Balanced Scorecard. dari penelitian ini didapat beberapa temuan yang harus diperbaiki diantaranya jaringan, aplikasi, evaluasi yang belum dilakukan secara optimal SOP yang belum diperbaharui, training terhadap penggunaan aplikasi masih kurang dipahami [5].

Triana, et., al [Analisis Kinerja Aplikasi Sistem Informasi Cuti Elektronik Dengan Menggunakan IT Balanced Scorecard] 
Penelitian yang berjudul Analisa Kinerja Sistem Informasi /Teknologi Informasi Pada BPPT dan PM Kota Salatiga Menggunakan Kerangka IT Balanced Scorecard". Tujuan penelitian ini adalah untuk menganalisis kinerja SI/TI pada BPPT \& PM Kota Salatiga. didapat hasil pada perspektif kontribusi organisasi mendapat hasil yang rendah, karena dalam penerapan aplikasi masih kurang efektif dan efisien dan masih banyak pegawai menggunakan proses manual, serta dalam penggunaan dana yang belum efektif bagi proses pengembangan aplikasi [4].

Penelitian berjudul Pengukuran Kinerja System Application and Product (SAP) Pada Wilmar Group Plantation Pontianak dengan tujuan penelitian menilai kinerja aplikasi SAP sebagai pendukung memberikan laporan kinerja tiap divisi. Hasil pengukuran menginformasikan bahwa SAP mampu mendukung kinerja karyawan Wilmar Group Plantation Pontianak dan hasil pencapaian keseluruhan mampu meningkatkan kinerja karyawan Wiliam Group Plantation [6].

Berdasarkan permasalahan pada penelitian, penelitian ini dilakukan untuk mengetahui seberapa besar tingkat kesuksesan kinerja aplikasi SiCute saat ini dan. Pengukuran kinerja aplikasi SiCute diukur menggunakan empat perspektif IT Balanced Scorecard yaitu, perspektif kontribusi organisasi, perspektif orientasi pengguna, perspektif keunggulan operasional dan perspektif orientasi masa depan. Sehingga dapat memberikan gambaran informasi yang jelas mengenai kinerja aplikasi SiCute BKDIKLATDA terhadap tujuan yang ingin dicapai untuk meningkatkan kinerja di masa mendatang.

\section{METODE PENELITIAN}

\subsection{Tinjauan Pustaka}

Konsep Balanced Scorecard pada tahun 1992 diperkenalkan oleh Kaplan dan Norton, konsep Balanced Scorecard dikembangkan untuk pengukuran kinerja finansial yang akan memberikan gambaran keadaan bisnis atas manajemen secara komprehensif. Pada Tahun 1997, Van Grembergen dan Van Bruggen mengadopsi Balanced Scorecard (BSC) untuk digunakan pada departemen Teknologi Informasi dalam organisasi. Menurut (Grembergen dan Haes) konsep Balanced Scorecard yang dikembangkan oleh Kaplan dan Norton dapat diterapkan ke dalam fungsi Teknologi Informasi dan proses-prosesnya ke dalam Balanced Scorecard dengan demikian IT berperan penting dalam mengolah informasi menjadi lebih akurat, seperti ditunjukan pada

Gambar 1 [7].

\begin{tabular}{|c|c|}
\hline $\begin{array}{l}\text { Balanced Scorecard } \\
\text { a. Finansial } \\
\text { b. Customer } \\
\text { c. Internal business } \\
\text { d. Learning and growth }\end{array}$ & $\begin{array}{l}\text { IT Balanced Scorecard } \\
\text { e. Corporate Contribution } \\
\text { f. Customer orientation } \\
\text { g. Internal excellence } \\
\text { h. Future orientation }\end{array}$ \\
\hline
\end{tabular}

Gambar 1. Perubahan Perspektif BSC Tradisional Menjadi Perspektif IT Balanced Scorecard

Triana, et., al [Analisis Kinerja Aplikasi Sistem Informasi Cuti Elektronik Dengan Menggunakan IT Balanced Scorecard] 
IT Balanced Scorecard merupakan salah satu kerangka kerja untuk menilai dan mengukur kinerja teknologi informasi yang didasarkan pada 4 perspektif, yaitu Perspektif Orientasi Pengguna, Perspektif Kontribusi Perusahaan, Perspektif Operasional, dan Perspektif Orientasi Masa Depan. IT Balanced Scorecard menyediakan pemaparan dan ulasan yang bersifat menyeluruh dan terstruktur, sehingga pengelola SI/TI dapat terus memantau perkembangan setiap aspek dari strategi penerapan teknologi informasi dengan mengacu kepada nilai dari masing-masing perspektif [8]. IT Balanced Scorecard bertujuan menyesuaikan perencanaan agar pengguna dapat melaksanakan aktivitas-aktivitas sistem informasi untuk kebutuhan organisasi, menyediakan pengukuran sesuai dengan kebutuhan dan tujuan organisasi serta menyediakan pengukuran untuk mengevaluasi efektivitas sistem informasi organisasi untuk mempertahankan dan meningkatkan kinerja sistem informasi agar mencapai hasil yang seimbang antar stakeholder [9].

\begin{tabular}{|c|c|}
\hline User Orientation & Business Contribution \\
\hline $\begin{array}{l}\text { How do user view the IT Department? } \\
\text { Mission } \\
\text { To be the preferred supplier of information } \\
\text { system } \\
\text { Objectives } \\
\text { a. Preferred supplier of applications } \\
\text { b. Preferred supplier of vs proposer of best } \\
\quad \text { solution } \\
\text { c. Partnership with users } \\
\text { d. User satisfaction }\end{array}$ & $\begin{array}{l}\text { How does management view the IT } \\
\text { department? } \\
\text { Mission } \\
\text { To obtain a reasonable Business Contribution } \\
\text { from IT } \\
\text { Objectives } \\
\text { a. Control of IT expenses } \\
b . \text { Business value of IT project } \\
\text { c. Provision of new business capabilities }\end{array}$ \\
\hline Operation Excellence & Future Orientation \\
\hline $\begin{array}{l}\text { How effective and efficient are the IT } \\
\text { processes? } \\
\text { Mission } \\
\text { To deliver effective and efficient IT applications } \\
\text { and services } \\
\text { Objectives } \\
\text { a. Efficient and effective developments } \\
\text { b. Efficient and effective operations }\end{array}$ & $\begin{array}{l}\text { How effective and efficient are the IT } \\
\text { processes? } \\
\text { Mission } \\
\text { To develop opportunities to answer future } \\
\text { challenges } \\
\text { Objectives } \\
\text { a. Training and education of IT staff } \\
\text { b. Expertise of IT staff } \\
\text { c. Research into emerging technologies } \\
\text { d. Age of application portfolio }\end{array}$ \\
\hline
\end{tabular}

Gambar 2. Perspektif IT Balanced Scorecard [9]

Pada Gambar 2 ditunjukan tabel empat perspektif IT Balanced Scorecard yaitu, Perspective business contribution dilakukan untuk mengevaluasi kinerja TI berdasarkan pandangan dari manajemen eksekutif. Evaluasi TI dipisahkan menjadi dua macam, yaitu jangka pendek, dan jangka panjang. Jangka pendek mengevaluasi finansial dari suatu perusahaan, sedangkan jangka Panjang mengevaluasi orientasi pada proyek dan fungsi IT itu sendiri. Perspective user orientation dilakukan untuk mengevaluasi kinerja TI berdasarkan cara pandang pengguna bisnis (pelanggan) dan lebih jauh lagi adalah pelanggan dari unit bisnis yang ada. Perspective operational excellence dilakukan untuk menilai kinerja TI berdasarkan efektifitas dan efisiensi dari proses IT dinilai oleh pihak manajemen. Perspective future orientation dilakukan untuk menilai kinerja TI berdasarkan cara pandang dari departemen itu sendiri, yaitu pelaksanaan, para praktisi dan profesional yang ada. 


\subsection{Diagram Hubungan Sebab Akibat}

Kelebihan menggunakan pengukuran dengan IT Balanced Scorecard adalah hasil yang didapat berupa sebuah perencanaan strategi yang komprehensif, seimbang dan terukur[10]. Pengukuran kinerja melalui pendekatan ini merujuk pada diagram hubungan sebab akibat untuk masing-masing perspektif. Pada perspektif ini apabila keahlian dan kualitas kinerja staf meningkat maka berpengaruh pada perspektif keunggulan operasional dimana menyebabkan peningkatan kegiatan operasional yang terkomputerisasi sehingga dapat memberikan kepuasan pengguna pada perspektif pengguna maka akan meningkat pula produktifitas staff dan kontribusi bisnis (Gambar 3)

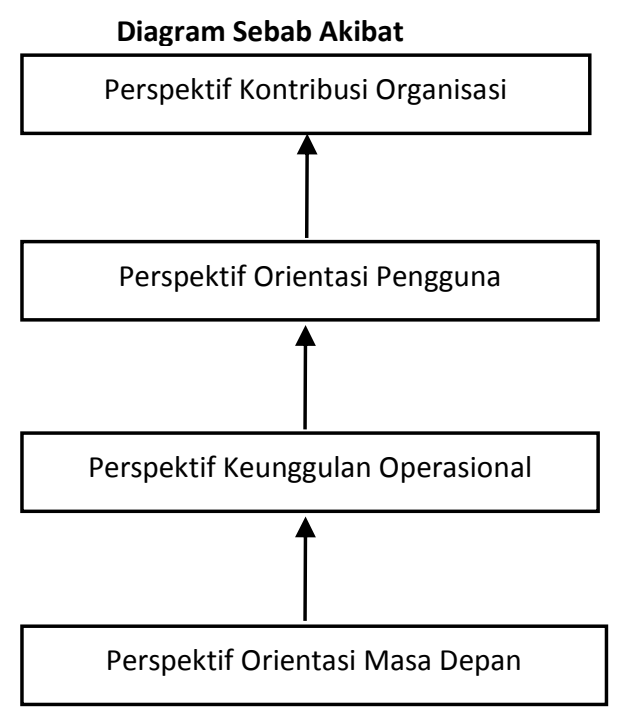

\begin{tabular}{|l|}
\multicolumn{2}{c}{ Gambar Hubungan Sebab Akibat } \\
JIKA \\
Keahlian dan kualitas kinerja staf dalam menggunakan \\
dan memanfaatkan IT yang terus berkembang \\
meningkat (Perspektif orientasi masa depan) \\
MAKA \\
Hal ini akan menghasilkan peningkatan kegiatan \\
operasional yang terkomputerisasi dan menambah \\
dukungan dalam proses bisnis (Perspektif keunggulan \\
operasional) \\
MAKA \\
Hal ini akan memberikan kepuasan debitur dan user \\
(perspektif orientasi pengguna) \\
MAKA \\
Hal ini akan meningkatkan produktivitas staf dan \\
kontribusi fungsi bisnis (Perspektif kontribusi organisasi) \\
\end{tabular}

Gambar 3. Diagram Hubungan Sebab Akibat

\subsection{Tahapan Penelitian}

Penelitian ini menggunakan pendekatan deskriptif kuantitatif. Penelitian dilakukan di Badan Kepegawaian, Pelatihan dan Pendidikan (BKDIKLATDA) Kota Salatiga. yang beralamat di jalan Pemuda No.1, Kota Salatiga, Jawa Tengah. Teknik pengumpulan data diperoleh dengan wawancara, dokumentasi dan penyebaran kuesioner kepada sejumlah responden yang berkaitan langsung dengan sistem aplikasi. Dalam pengukuran kinerja aplikasi SiCute menggunakan kerangka IT Balanced Scorecard yang memiliki 4 perspektif didalamnya, yaitu perspektif kontribusi organisasi, perspektif orientasi pengguna, perspektif keunggulan operasional dan perspektif orientasi masa depan. Penelitian dilakukan dengan melalui enam tahapan penelitian seperti ditunjukan pada Gambar 4.

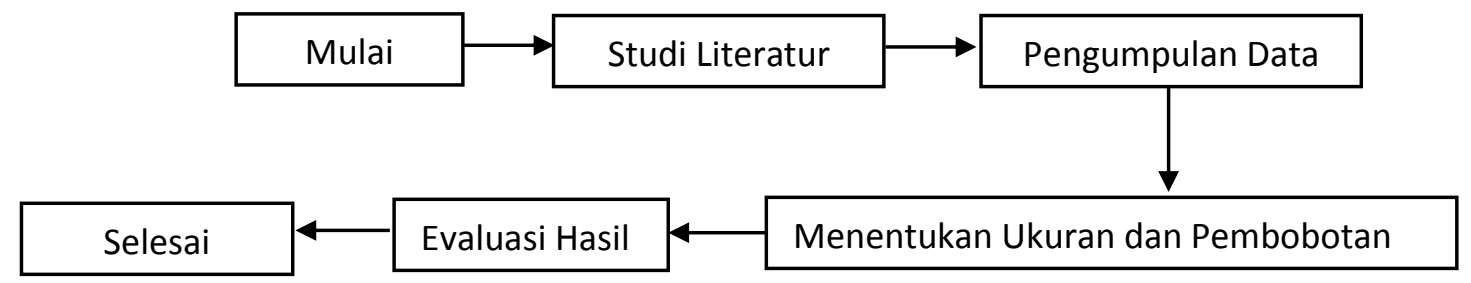

Gambar 4. Tahapan Penelitian

Penelitian diawali mempelajari literatur yang berkaitan dengan pengukuran kinerja menggunakan IT Balanced Scorecard. dengan peneliti mempelajari literature ini, diharapkan

Triana, et., al [Analisis Kinerja Aplikasi Sistem Informasi Cuti Elektronik Dengan Menggunakan IT Balanced Scorecard] 
dapat mengetahui gambaran terkait pengukuran kinerja berdasarkan IT Balanced Scorecard. Kemudian melakukan pengumpulan data, data didapat berdasarkan penyebaran kuesioner daftar pertanyaan kepada sejumlah responden dan diperkuat dengan melakukan wawancara. Selanjutnya pada tahapan ketiga dilanjutkan dengan mempelajari visi, misi dan rencana strategis perusahaan. Kemudian berlanjut menentukan ukuran dari IT Balanced Scorecard berdasarkan masing-masing perspektif yang diturunkan dari visi, misi BKDIKLATDA, lalu selanjutnya menentukan pembobotan berdasarkan ukuran dari masing-masing parameter yang telah ditetapkan dan kemudian dilakukan evaluasi hasil dari pengukuran kinerja. Adapun skala yang digunakan dalam perhitungan pengukuran aplikasi SiCute menggunakan lima skala yaitu, sangat setuju bernilai 5 , tidak setuju bernilai 4 , netral bernilai 3 , tidak setuju bernilai 2 , dan sangat tidak setuju bernilai 1 .

\section{HASIL DAN PEMBAHASAN}

Dalam menentukan ukuran strategis untuk setiap perspektif diperoleh berdasarkan tujuan masing-masing perspektif IT Balanced Scorecard sehingga menjadi beberapa macam ukuran. Pada setiap ukuran strategis harus memiliki sasaran strategis, adapun ukuran dan sasaran strategis dari tiap perspektif ditentukan dan disetujui oleh peneliti dan pimpinan BKDIKLATDA Kota Salatiga. Kemudian setelah menentukan ukuran maupun sasaran strategis dari keempat perspektif, maka dilakukan pengukuran kinerja mengenai aplikasi SiCute, dari data kuesioner responden yang telah dikumpulkan, data yang telah dikumpulkan dihitung jumlah jawaban dari tiap responden untuk mendapatkan kondisi aktual perusahaan. Selanjutya melakukan perhitungan kinerja terhadap nilai pencapaian dari masing-masing ukuran strategis (Tabel 1).

Tabel 1. Hasil Pengolahan Data

\begin{tabular}{|c|c|c|c|c|}
\hline \multicolumn{5}{|c|}{ Perspektif Kontribusi Organisasi } \\
\hline Tujuan Strategis & Ukuran Strategis & Sasaran & $\begin{array}{l}\text { Kondisi } \\
\text { Aktual }\end{array}$ & Pencapaian \\
\hline \multirow{2}{*}{$\begin{array}{l}\text { A. Pengefektifan } \\
\text { dan } \\
\text { pengefisienan } \\
\text { produktivitas } \\
\text { karyawan }\end{array}$} & $\begin{array}{l}\text { A1. Penggunaan aplikasi dapat meningkatkan } \\
\text { produktivitas kerja bagi pegawai }\end{array}$ & $100 \%$ & $96 \%$ & $96 \%$ \\
\hline & $\begin{array}{l}\text { A2. Hasil dapat membantu Pejabat Pengambil } \\
\text { Keputusan (PKK) dalam mengambil keputusan }\end{array}$ & $95 \%$ & $100 \%$ & $105,26 \%$ \\
\hline \multicolumn{4}{|c|}{ TOTAL } & $201,26 \%$ \\
\hline \multicolumn{4}{|c|}{ RATA-RATA } & $100,63 \%$ \\
\hline \multirow{3}{*}{$\begin{array}{ll}\text { B. } & \text { Peningkatan } \\
\text { kontribusi } \\
\text { bisnis fungsi } \\
\text { bisnis }\end{array}$} & $\begin{array}{l}\text { B1. Penggunaan dana pengembangan aplikasi } \\
\text { SiCute sudah efektif }\end{array}$ & $95 \%$ & $80 \%$ & $84,21 \%$ \\
\hline & $\begin{array}{l}\text { B2. Hasil dari SiCute dapat membantu pengelola } \\
\text { meningkatkan kinerja }\end{array}$ & $90 \%$ & $80 \%$ & $88,89 \% \%$ \\
\hline & $\begin{array}{l}\text { B3. Aplikasi SiCute menjadi kekuatan dalam } \\
\text { mengelola data cuti pegawai }\end{array}$ & $100 \%$ & $92 \%$ & $92 \%$ \\
\hline \multicolumn{4}{|c|}{ TOTAL } & $265,10 \%$ \\
\hline \multicolumn{4}{|c|}{ RATA-RATA } & $\mathbf{8 6 , 3 7 \%}$ \\
\hline \multicolumn{5}{|c|}{$\begin{array}{l}\text { Perspektif Orientasi Pengguna } \\
\end{array}$} \\
\hline \multirow{3}{*}{$\begin{array}{ll}\text { A. } & \text { Meningkatkan } \\
& \text { kepuasan } \\
\text { pengguna } \\
\text { terhadap SiCute }\end{array}$} & $\begin{array}{l}\text { A1. Pengguna puas dengan layanan jasa dari } \\
\text { aplikasi SiCute }\end{array}$ & $90 \%$ & $92 \%$ & $102 \%$ \\
\hline & $\begin{array}{l}\text { A2. Fasilitas dalam aplikasi mudah dipahami dan } \\
\text { digunakan }\end{array}$ & $85 \%$ & $80 \%$ & $94,1 \%$ \\
\hline & $\begin{array}{l}\text { A3. SiCute membantu dalam mengurangi } \\
\text { kesalahan dalam menjalankan tugas }\end{array}$ & $85 \%$ & $78,3 \%$ & $92,16 \%$ \\
\hline
\end{tabular}

Triana, et., al [Analisis Kinerja Aplikasi Sistem Informasi Cuti Elektronik Dengan Menggunakan IT Balanced Scorecard] 


\begin{tabular}{|c|c|c|c|c|}
\hline \multicolumn{4}{|c|}{ TOTAL } & \multirow{2}{*}{$\begin{array}{c}\mathbf{2 8 8 , 1 3 \%} \\
\mathbf{9 6 , 0 4 \%}\end{array}$} \\
\hline \multicolumn{4}{|c|}{ RATA-RATA } & \\
\hline \multirow[t]{3}{*}{$\begin{array}{l}\text { B. } \begin{array}{l}\text { Meningkatkan } \\
\text { sumber daya }\end{array}\end{array}$} & $\begin{array}{l}\text { B1. Penggunaan Sicute menjadikan pekerjaan lebih } \\
\text { efektif dan efisien }\end{array}$ & $90 \%$ & $88,3 \%$ & $98,1 \%$ \\
\hline & B2. Kemudahan dalam memperoleh informasi cuti & $95 \%$ & $80 \%$ & $84,21 \%$ \\
\hline & B3. Hasil kerja SiCute sesuai dengan rencana kerja & $90 \%$ & $75 \%$ & $83,33 \%$ \\
\hline \multicolumn{4}{|c|}{ TOTAL } & $265,69 \%$ \\
\hline \multicolumn{4}{|c|}{ RATA-RATA } & $\mathbf{8 8 , 5 6 \%}$ \\
\hline \multicolumn{5}{|c|}{ Perspektif Keunggulan Operasional } \\
\hline \multirow{3}{*}{$\begin{array}{ll}\text { A. } & \begin{array}{l}\text { Peningkatan } \\
\text { kegiatan } \\
\text { operasional }\end{array}\end{array}$} & A1. fasilitas komputerisasi yang memadai & $85 \%$ & $85 \%$ & $100 \%$ \\
\hline & $\begin{array}{l}\text { A2. Penggunaan aplikasi SiCute proses pelayanan } \\
\text { dan proses data cuti menjadi tepat waktu }\end{array}$ & $85 \%$ & $80 \%$ & $94,12 \%$ \\
\hline & $\begin{array}{l}\text { A3. Membantu pencapaian kerja semakin lebih } \\
\text { baik }\end{array}$ & $95 \%$ & $75 \%$ & $78,95 \%$ \\
\hline \multicolumn{4}{|c|}{ TOTAL } & $273,07 \%$ \\
\hline \multicolumn{4}{|c|}{ RATA-RATA } & $91,02 \%$ \\
\hline \multirow{4}{*}{$\begin{array}{ll}\text { B. } & \text { meningkatkan } \\
& \text { kualitas sistem } \\
& \text { layanan }\end{array}$} & $\begin{array}{l}\text { B1. Penggunaan SiCute dapat meningkatkan } \\
\text { kualitas sistem layanan }\end{array}$ & $90 \%$ & $95 \%$ & $105,56 \%$ \\
\hline & $\begin{array}{l}\text { B2. Aplikasi SiCute mudah ditangani jika terjadi } \\
\text { masalah }\end{array}$ & $85 \%$ & $85 \%$ & $100 \%$ \\
\hline & $\begin{array}{l}\text { B3. Memenuhi kebutuhan dalam mengelola data } \\
\text { cuti }\end{array}$ & $90 \%$ & $80 \%$ & $88,89 \%$ \\
\hline & B4. Penyimpanan data lebih aman & $90 \%$ & $75 \%$ & $83,33 \%$ \\
\hline \multicolumn{4}{|c|}{ TOTAL } & $\mathbf{3 7 7 , 7 8 \%}$ \\
\hline \multicolumn{4}{|c|}{ RATA-RATA } & $94,44 \%$ \\
\hline \multicolumn{5}{|c|}{$\begin{array}{ll}\text { Perspektif Orientasi Masa Depan } \\
\end{array}$} \\
\hline \multirow{2}{*}{$\begin{array}{ll}\text { A. } & \text { Peningkatan } \\
& \text { kualitas } \\
& \text { penggunaan } \\
& \text { Aplikasi SiCute } \\
\end{array}$} & $\begin{array}{l}\text { A1. Meningkatkan keahlian karyawan dalam } \\
\text { bekerja }\end{array}$ & $85 \%$ & $82 \%$ & $96,1 \%$ \\
\hline & $\begin{array}{l}\text { B2. Berkurangnya kesalahan yang dilakukan oleh } \\
\text { manusia dan informasi diperoleh cepat dan tepat }\end{array}$ & $95 \%$ & $87 \%$ & $91,2 \%$ \\
\hline \multicolumn{4}{|c|}{$\begin{array}{l}\text { TOTAL } \\
\end{array}$} & $187,31 \%$ \\
\hline \multicolumn{4}{|c|}{ RATA-RATA } & $93,65 \%$ \\
\hline \multirow{2}{*}{$\begin{array}{ll}\text { B. } & \text { Peningkatan } \\
& \text { sistem dengan } \\
\text { pemanfaatan } \\
\text { teknologi baru }\end{array}$} & $\begin{array}{l}\text { Akan terus mengikuti teknologi informasi pada } \\
\text { masa mendatang }\end{array}$ & $95 \%$ & $90 \%$ & $94,74 \%$ \\
\hline & $\begin{array}{l}\text { Peningkatan kinerja dengan pemanfaatan teknologi } \\
\text { baru }\end{array}$ & $100 \%$ & $90 \%$ & $90 \%$ \\
\hline \multicolumn{4}{|c|}{$\begin{array}{l}\text { TOTAL } \\
\end{array}$} & $184,74 \%$ \\
\hline \multicolumn{4}{|c|}{ RATA-RATA } & $\mathbf{9 2 , 3 7 \%}$ \\
\hline
\end{tabular}

Tahapan selanjutnya dilakukan pembobotan tujuan strategis pada masing-masing perspektif IT Balanced Scorecard. Bobot ditetapkan dengan berdasarkan hasil kesepakatan dan persetujuan dengan pihak Badan Kepegawaian, Pelatihan dan Pendidikan (BKDIKLATDA) Kota Salatiga pada Tabel 2. Tabel 2 akan memaparkan hasil tingkat pemenuhan target pada setiap perspektif IT Balanced Scorecard.

Tabel 2. Hasil Pembobotan Tujuan Strategis

\begin{tabular}{|c|l|l|c|c|}
\hline \multicolumn{1}{|c|}{ Perspektif } & \multicolumn{1}{|c|}{ Tujuan Strategis } & Bobot & $\begin{array}{c}\text { Hasil } \\
\text { Ukuran }\end{array}$ & $\begin{array}{c}\text { Hasil } \\
\text { Tujuan }\end{array}$ \\
\hline \multirow{2}{*}{$\begin{array}{l}\text { Kontribusi } \\
\text { Organisasi }\end{array}$} & $\begin{array}{l}\text { Pengefektifan dan Pengefisienan } \\
\text { produktivitas pegawai }\end{array}$ & $55 \%$ & $100,63 \%$ & $55,35 \%$ \\
\cline { 2 - 5 } & Peningkatan Kontribusi Fungsi Bisnis & $45 \%$ & $88,37 \%$ & $39,76 \%$ \\
\hline
\end{tabular}

Triana, et., al [Analisis Kinerja Aplikasi Sistem Informasi Cuti Elektronik Dengan Menggunakan IT Balanced Scorecard] 


\begin{tabular}{|l|l|l|l|l|}
\hline TOTAL & Meningkatkan kepuasan pengguna & $50 \%$ & $96,04 \%$ & $48,02 \%$ \\
\hline \multirow{3}{*}{$\begin{array}{l}\text { Orientasi } \\
\text { Pengguna }\end{array}$} & Meningkatkan sumber daya pengguna & $55 \%$ & $88,56 \%$ & $48,71 \%$ \\
\hline \multirow{3}{*}{ TOTAL } & Meningkatkan kegiatan operasional & $55 \%$ & $91,02 \%$ & $50,06 \%$ \\
\hline $\begin{array}{l}\text { Keunggulan } \\
\text { Operasional }\end{array}$ & Meningkatkan kualitas sistem aplikasi & $50 \%$ & $94,44 \%$ & $47,22 \%$ \\
\hline TOTAL & Peningkatan kualitas penggunaan & $45 \%$ & $93,65 \%$ & $42,14 \%$ \\
\cline { 2 - 5 } $\begin{array}{l}\text { Orientasi Masa } \\
\text { Depan }\end{array}$ & $\begin{array}{l}\text { Peningkatan pengembangan sistem dengan } \\
\text { pemanfaatan teknologi informasi baru }\end{array}$ & $45 \%$ & $92,37 \%$ & $41,57 \%$ \\
\hline TOTAL & \multicolumn{3}{|l|}{} & $\mathbf{8 3 , 7 1 \%}$ \\
\hline
\end{tabular}

Pada tabel 3 adalah hasil pengukuran kinerja aplikasi SiCute hingga total nilai IT Balanced Scorecard pada perspektif Kontribusi Organisasi, Orientasi Pengguna, Orientasi Operasional, dan Orientasi Masa Depan.

Tabel 3. Hasil Pengukuran

\begin{tabular}{|l|c|}
\hline \multicolumn{1}{|c|}{ Perspektif } & Hasil Pengukuran \\
\hline Kontribusi Organisasi & $23,77 \%$ \\
\hline Orientasi Pengguna & $24,18 \%$ \\
\hline Orientasi Operasional & $24,07 \%$ \\
\hline Orientasi Masa Depan & $20,92 \%$ \\
\hline \multicolumn{1}{|c|}{ TOTAL } & $\mathbf{9 2 , 9 4 \%}$ \\
\hline
\end{tabular}

Setelah melakukan pengukuran kinerja dari masing-masing perspektif yang ada pada IT Balanced Scorecard, maka selanjutnya dilakukan evaluasi hasil pengukuran kinerja terhadap rata-rata pencapaian yang diperoleh dari tiap perspektif. Yang pertama pada perspektif kontribusi organisasi memiliki nilai $95,11 \%$ dimana nilai ini menunjukkan bahwa pencapaian perspektif kontribusi organisasi berada di level yang sangat baik, yaitu level very good. Pencapaian nilai ini terjadi dikarenakan pengefektifan dan pengefisienan produktivitas karyawan. Selain itu juga peningkatan kontribusi fungsi bisnis dalam menunjang kebutuhan pengembangan sistem pada Badan Kepegawaian, Pelatihan dan Pendidikan Kota Salatiga. Pada perspektif orientasi pengguna menunjukan nilai $96,73 \%$ yang berada pada level sangat baik, yaitu level very good. Pencapaian ini dapat terjadi karena pada kepuasan pengguna yang cukup tinggi pada sistem cukup tinggi serta fasilitas dalam sistem mudah dipahami dan digunakan oleh pengguna. sehingga meningkatkan sumber daya pengguna menjadikan pekerjaan efektif dan efisien dan mudah memperoleh informasi cuti dan mampu bersaing secara kompetitif.

Perspektif selanjutnya yaitu perspektif keunggulan operasional memiliki nilai 97,28\% dimana nilai ini menunjukan bahwa perspektif ini sudah sangat baik. Pencapaian ini terjadi dikarenakan peningkatan dari kegiatan operasional yang terkomputerisasi serta meningkatkan kualitas sistem yang baik dalam hasil pemgembangan sistem dengan semakin lebih baik dan berkualitas, sehingga kualitas yang diberikan teknologi informasi dapat semakin terlihat oleh Badan Kepegawaian, Pelatihan dan Pendidikan dari hasil pengukuran kinerja aplikasi SiCute 
yang berada pada kondisi very good ini. Selanjutnya perspektif yang keempat adalah perspektif orientasi masa depan yang memiliki nilai $83,71 \%$ dimana pencapaian pada perspektif orientasi masa depan juga memiliki nilai yang sangat baik, yaitu berada pada level very good. Hal ini bisa terjadi karena peningkatan kualitas teknologi informasi karena memiliki karyawan yang berkualitas dan keahlian maupun pengalaman yang dimiliki cukup banyak pada bidangnya masing-masing. Bukan hanya itu saja BKDIKLATDA juga melakukan pelatihan terhadap teknologi informasi untuk menambah pengetahuan dan keahlian. Dan dalam pengembangan sistem pun terus mendukung pencapaian hasil yang baik dengan terus mengikuti perkembangan teknologi informasi dimasa mendatang (Tabel 4).

Tabel 4. Evaluasi Hasil Pengukuran

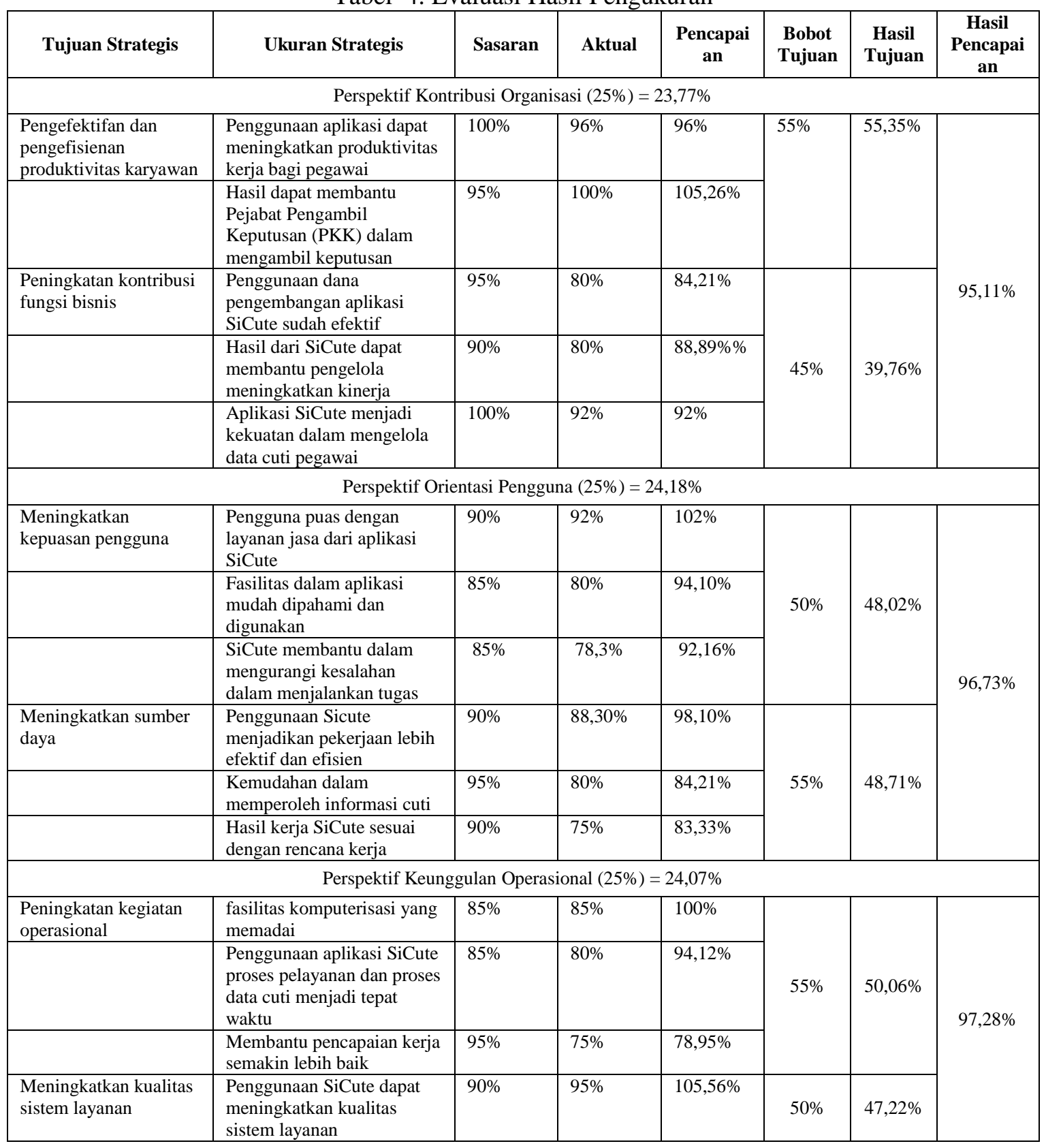

Triana, et., al [Analisis Kinerja Aplikasi Sistem Informasi Cuti Elektronik Dengan Menggunakan IT Balanced Scorecard] 


\begin{tabular}{|c|c|c|c|c|c|c|c|}
\hline & $\begin{array}{l}\text { Aplikasi SiCute mudah } \\
\text { ditangani jika terjadi } \\
\text { masalah }\end{array}$ & $85 \%$ & $85 \%$ & $100 \%$ & & & \\
\hline & $\begin{array}{l}\text { Memenuhi kebutuhan } \\
\text { dalam mengelola data cuti }\end{array}$ & $90 \%$ & $80 \%$ & $88,89 \%$ & & & \\
\hline & $\begin{array}{l}\text { Penyimpanan data lebih } \\
\text { aman }\end{array}$ & $90 \%$ & $75 \%$ & $83,33 \%$ & & & \\
\hline \multicolumn{8}{|c|}{ Perspektif Masa Depan $(25 \%)=20,92 \%$} \\
\hline \multirow{2}{*}{$\begin{array}{l}\text { Peningkatan kualitas } \\
\text { penggunaan Aplikasi } \\
\text { SiCute }\end{array}$} & $\begin{array}{l}\text { Meningkatkan keahlian } \\
\text { karyawan dalam bekerja }\end{array}$ & $85 \%$ & $82 \%$ & $96,10 \%$ & \multirow[b]{2}{*}{$45 \%$} & \multirow[b]{2}{*}{$42,14 \%$} & \multirow{4}{*}{$83,71 \%$} \\
\hline & $\begin{array}{l}\text { Berkurangnya kesalahan } \\
\text { yang dilakukan oleh } \\
\text { manusia dan informasi } \\
\text { diperoleh cepat dan tepat }\end{array}$ & $95 \%$ & $87 \%$ & $91,20 \%$ & & & \\
\hline $\begin{array}{l}\text { Peningkatan sistem } \\
\text { dengan pemanfaatan } \\
\text { teknologi baru }\end{array}$ & $\begin{array}{l}\text { Akan terus mengikuti } \\
\text { teknologi informasi pada } \\
\text { masa mendatang }\end{array}$ & $95 \%$ & $90 \%$ & $94,74 \%$ & \multirow[t]{2}{*}{$45 \%$} & \multirow[t]{2}{*}{$41,57 \%$} & \\
\hline & $\begin{array}{l}\text { Peningkatan kinerja dengan } \\
\text { pemanfaatan teknologi baru }\end{array}$ & $100 \%$ & $90 \%$ & $90 \%$ & & & \\
\hline
\end{tabular}

Dengan penggunaan Sistem Informasi Cuti Elektronik (SiCute) mampu memberikan kontribusi terhadap organisasi, mendukung pada orientasi pengguna, mendukung kegiatan operasional, serta mampu bersaing di masa depan. Dimana hal ini dapat dilihat pada hasil nilai perolehan pengukuran dari empat perspektif IT Balanced Scorecard yang pertama yaitu perspektif kontribusi organisasi mendapat nilai pengukuran sebesar 95,11\% dengan hasil akhir pengukuran dari masing-masing perspektif sebesar $23,77 \%$, pada perspektif orientasi pengguna sebesar 96,73\% dengan hasil akhir pengukuran dari masing-masing perspektif sebesar $24,18 \%$, yang berikutnya yaitu perspektif keunggulan operasional sebesar $97,28 \%$ dengah hasil akhir pengukuran dari masing-masing perspektif sebesar $24,07 \%$, dan yang terakhir yaitu perspektif orientasi masa perspektif sebesar 83,71 dengan hasil akhir pengukuran dari masing-masing perspektif sebesar 20,92\%. Maka hasil akhir dari pengukuran kinerja Sistem informasi Cuti Elektronik dengan menggunakan IT Balanced Scorecard memperlihatkan pencapaian hasil nilai IT Balanced Scorecard pada Badan Kepegawaian, Pelatihan dan Pendidikan sebesar 92,94\%. Dimana ini menandakan kinerja aplikasi SiCute telah berada pada level sangan baik atau very good.

\section{KESIMPULAN}

Perhitungan dengan IT Balanced Scorecard diperoleh hasil pencapaian keseluruhan dari masing-masing perspektif $100 \%$ dibagi dengan 4 perspektif IT Balanced Scorecard sehingga keempat perspektif tersebut mempunyai nilai bobot $25 \%$. Perspektif mendapat nilai tertinggi adalah perspektif orientasi pengguna dengan nilai hasil pencapaian keseluruhan sebesar 24,18\%, kedua adalah perspektif keunggulan operasional dengan nilai keseluruhan sebesar 24,07\%, kemudian yang ketiga yaitu perspektif kontribusi organisasi dengan nilai hasil keseluruhan sebesar $23,77 \%$, kemudian yang terakhir perspektif orientasi masa depan dengan nilai hasil keseluruhan sebesar 20,29\%. Dilihat dari hasil pencapaian keseluruhan pengukuran kinerja SiCute melalui masing-maisng perspektif IT Balanced Scorecard di Badan Kepegawaian, Pelatihan dan Pendidikan dilihat bahwa hasil pencapaian dapat meningkatkan kinerja organisasi pada tiap perspektif sehingga berada pada level very good. Total hasil pengukuran sebesar $92,94 \%$. Dari total angka tersebut dapat menjawab keinginan dan kemudahan mengolah data 
dan secara keseluruhan SiCute sudah mampu membantu kualitas kinerja karyawan dalam pekerjaan.

\section{SARAN}

Dalam pencapaian yang sudah didapat melalui dari pengukuran kinerja aplikasi SiCute dengan menggunakan IT Balanced Scorecard sudah memperlihatkan hasil yang sangat baik. Hasil pencapaian yang diperoleh harus tetap dipertahankan dan jika perlu ditingkatkan untuk menunjang kinerja di Badan Kepegawaian, Pendidikan dan Pelatihan Kota Salatiga menjadi lebih baik dimasa mendatang. Tentunya dalam peningkatan kinerja perlu didukung dengan sumber daya yang ahli di bidangnya supaya dapat melakukan pengembangan yang maksimal untuk menghadapi perubahan yang secara terus-menerus terjadi. Pada penelitian ini hanya terbatas yang berfokus pada aplikasi sistem informasi elektronik cuti (SiCute). Diharapkan kedepannya peneliti supaya dapat melakukan penelitian menggunakan metode penelitian secara lebih luas.

\section{UCAPAN TERIMA KASIH}

Terima kasih kepada Tuhan yang Maha Kuasa yang selalu menuntun saya selama ini dan terima kasih juga kepada kedua orang tua saya, keluarga, dosen pembimbing dan temanteman saya yang selalu mendukung saya.

\section{DAFTAR PUSTAKA}

[1] A. Zuniawan, O. Julyanto, Y. B. Suryono, and Z. F. Ikatrinasari, "Implementasi Metode Balanced Scorecard Untuk Mengukur Kinerja di Perusahaan Engineering (Study Case PT. MSE),” Journal Industrial Servicess, Vol. 5, No. 2, pp. 251-256, 2020, doi: 10.36055/jiss.v5i2.8008.

[2] J. S. Informasi, S. Pontianak, J. Merdeka, and N. Pontianak, "Pengukuran Kinerja Aplikasi SiCUNDO Menggunakan Metode IT Balanced Scorecard,” Vol. 1, pp. 1-11.

[3] S. Kosasi, "Pengukuran Kinerja Web Brinet System Dengan Metode IT Balanced Scorecard," Jurnal Buana Informatika, Vol. 6, No. 1, pp. 1-10, 2015, doi: 10.24002/jbi.v6i1.403.

[4] G. S. Legoh and J. J. C. Tambotoh. 2015, “Analisa Kinerja Sistem Informasi/Teknologi Informasi pada BPPT dan PM Kota Salatiga Menggunakan Kerangka IT Balanced Scorecard ISBN: 979-26-0280-1 ISBN: 979-26-0280-1," pp. 403-407.

[5] S. Wiyono and A. R. Tanaamah. 2017, "Analisis Kinerja SI/TI pada PDAM Kota Salatiga Menggunakan Kerangka IT Balanced Scorecard," Jurnal Buana Informatika, Vol. 8, No. 4, pp. 181-192, doi: 10.24002/jbi.v8i4.1442.

[6] D. Fitriani. 2016, "Pengukuran Kinerja System Application and Product (Sap) pada Wilmar Group Plantation Pontianak,” CogITo Smart Journal, Vol. 1, No. 1, p. 33, doi: 10.31154/cogito.v1i1.4.33-44.

Triana, et., al [Analisis Kinerja Aplikasi Sistem Informasi Cuti Elektronik Dengan Menggunakan IT Balanced Scorecard] 
[7] W. Grembergen and S. Haes. 2005, "Measuring and Improving Information Technology Governance Through The Balanced Scorecard, ”Information Systems Control Journal.

[8] A. Cram. 2007, "The IT Balanced Scorecard Revisited," Information Systems Control Journal.

[9] D. Y. Nainggolan and A. F. Wijaya,. 2019, “Analisis Kinerja Sistem Pengolahan Data Berbasis Web Menggunakan IT Balanced Scorecard Sebagai Sarana Untuk Menunjang Kinerja Pegawai pada Badan Pusat Statistik (BPS) Kabupaten Sragen," Jurnal SITECH: Sistem Informasi dan Teknologi, Vol. 2, No. 1, pp. 87-94, doi: 10.24176/sitech.v2i1.3350.

[10] A. F. Syarif, P. N. Basuki, and A. F. Wijaya. 2018, "Analisa Kinerja Sistem Informasi/ Teknologi Informasi pada PT. Bank Central Asia Menggunakan Kerangka IT Balanced Scorecard," JSI: Jurnal Sistem Informasi (E-Journal), Vol. 10, No. 1, pp. 1491-1502, doi: 10.36706/jsi.v10i1.8039. 